\title{
"Serious and Complex IIIness" in Quality Improvement and Policy Reform for End-of-life Care
}

\author{
Joanne Lynn, MD, Janet Heald Forlini, JD
}

\begin{abstract}
Americans are living longer - a mark of success in public health and medical care - but more will live the last few years with progressive illness and disability. The dominant conception of care delivery separates "aggressive" or life-extending care from "palliative" or death-accepting care, with an assumed "transition" between them. The physiology and the experience of this population are mismatched in this model. Here, we propose a more useful category for public policy and clinical quality improvement: persons who will die as a result of "serious and complex illness." Delivery system changes could ensure reliable, continuous, and competent care to this population.
\end{abstract}

KEY WORDS: health policy; serious and complex illness. J GEN INTERN MED 2001;16:315-319.

M ost Americans no longer die as we did until just half a century ago of infections, accidents, and organ system failures that usually kill quickly. Instead, better medical interventions, lifestyles, and public health have given us the opportunity to grow old, accumulate chronic conditions, and die slowly. The average American who survives childhood now has a life expectancy of about 80 years, and by then, most of us accumulate a few serious conditions with interacting and competing causes of disability and discomfort. ${ }^{1}$ For three quarters of Americans, the last year of life will include a diagnosis of heart failure, obstructive lung disease, stroke, dementia, or cancer (C. Hogan, personal communication, 1998). Once such an illness becomes substantially disabling, it worsens over months or years and eventually causes death. This last phase of serious illness has not been apparent until the past few decades.

In recent legislation and other federal government actions, this new category is sometimes described as serious and complex illness, a term first used in the 1997 "Health Insurance Bill of Rights Act." ${ }^{2}$ When President Clinton implemented that bill in federal agencies, having a "serious and complex illness" protected patients from suddenly losing a physician when a managed care organi-

From the RAND Center to Improve Care of the Dying (JL) Arlington, Va; Senate Special Committee on Aging Minority Office (JHF), Washington, DC.

Address correspondence to Dr. Lynn: RAND Center to Improve Care of the Dying, 1200 S. Hayes St., Arlington VA 22202 (e-mail: JLynn@rand.org). zation altered provider panels. ${ }^{3}$ Since "serious and complex illness" had no definition in legislative history or in professional literature, the Health Care Financing Administration contracted with the Institute of Medicine to investigate and report possible definitions. ${ }^{4}$ The Institute recommended that managed care organizations be allowed to work with this category without it being given a precise meaning.

Serious and complex illness may well be the moniker that our society has been seeking when we look to tailor care for those with substantial chronic illness. One way of classifying chronic illness would be to split the category 3 ways. In the first group are conditions that are progressive but not particularly life-threatening, such as osteoarthritis, hearing and vision deficits, and dental decay. In the second group are conditions that are not progressive, such as mental retardation. In the third group are conditions that are progressive and eventually fatal - those for whom the chronic illness is "serious." Recognition of this population's special characteristics could help to organize knowledge and administer benefits.

"Serious and complex (and eventually fatal)" illness seems more appropriate for most uses than is the phrase "terminally ill," which is a quite ambiguous and restrictive category, though commonly used. ${ }^{5,6}$ "Serious and complex" conditions are seriously disabling and will worsen until death. Virtually all such conditions require complex organizing of services over time. This paper aims to encourage internists to consider the special service needs of individuals with such conditions. Adopting the terminology "serious and complex illness" rather than "terminal illness" and providing services more directly targeted to the needs of this population might be useful in targeting quality improvement work and in shaping public policy. This paper discusses the problems with the current categorizations and language, describes financial and structural barriers to appropriate care, and provides examples of recent strides in improved care for individuals facing the end of life.

\section{PROBLEMS WITH CURRENT TERMINOLOGY FOR END-OF-LIFE CARE}

About one fifth of us will die with a reasonably recognizable course of illness, during which the patient is 
given a dire diagnosis, loses weight, takes to bed, and dies within a few weeks or months. ${ }^{7}$ Nonhematologic malignancies such as lung and colon cancer most commonly follow this course. ${ }^{6}$ At least two thirds of us will die at the end of a very different course. ${ }^{7}$ We will have 1 or more serious chronic diseases - heart, lung, or cognitive failure are most common. Our medical conditions will gradually restrict our activities and will cause repeated bouts of serious exacerbations with hospitalizations.

However, no distinct "terminal" period will mark the period just before death. Instead, the week in which we die will start like any other, then a pneumonia, pulmonary embolus, stroke, heart attack, arrhythmia, or some other rather unpredictable calamity will arise and quickly overwhelm the patient's terribly diminished reserves. One investigation used a well-calibrated statistical model to predict survival time among patients with advanced heart failure, defined as New York Heart Association Class III with 3 medications (unless unable to tolerate) and ejection fraction under $30 \%$ if measured. The median patient still had a $50 \%$ chance of living for 6 months on the day before the day he or she died. ${ }^{8}$ These patients could not walk across a large room, could not eat a full meal, and certainly could not manage their households directly. However, the timing of death remained quite uncertain, often right up to the day before death.

These patients live better with specially tailored care as they confront symptoms and the disquietude of eventual death. ${ }^{9}$ However, they will not readily qualify for hospice, since Medicare requires that hospice patients be "terminally ill," which requires reliable prognostication that life span will be less than 6 months. Seeking to enroll persons with fatal but unpredictable illnesses into hospice illuminates a serious problem in Medicare's definition of "terminally ill": the statute does not actually articulate the dividing line that physicians should use for the prognostic estimate. The statutory language is left open to interpretation - the just barely qualified patient could be "more likely than not to die within 6 months" or "virtually certain to die within 6 months." The latter is the definition that many argue the Health and Human Services Office of the Inspector General seemed to be applying when it conducted its investigations of fraud in hospice programs. ${ }^{10,11}$ The distinction is an important one from a public policy standpoint: many entire illness types, such as heart failure, would not qualify under some interpretations of the 6-month rule though they would often qualify under others. ${ }^{6}$

The diagnosis of "terminal" often carries with it the implication that the end of life is approaching and the focus turns to attending to completion of life tasks, spiritual issues, and physical comfort ${ }^{12}$ - all of which are important concerns and extremely appropriate for that population for whom nothing more can be done. But there is a different set of individuals - those with "serious and complex" illnesswho have the disease(s) from which they are likely to die but are not in the last few weeks and months of life. For these people, the focus instead is likely to be continuing to run businesses, initiating relationships, and otherwise to act like people who might continue to live for some time. If prognosis is actually ambiguous, patients may well chafe under the expectations and restrictions that society has come to apply to those who are labeled as "terminal."

\section{"SERIOUS AND COMPLEX ILLNESS": A MORE APPROPRIATE CATEGORY?}

The category of "serious and complex illness" would be more congruent with the special needs of persons who are quite ill and will gradually worsen until death. "Serious and complex" applies to patients with conditions that are already quite disabling, are expected to be fatal, and require ongoing health care. For such patients, priorities often change. In addition to wanting prevention of and rescue from physiological disturbance, people with "serious and complex illness" often have priorities that are difficult to meet: continuity and reliability over time, comprehensive services, advance planning, and symptom relief. In these respects, they are like hospice patients. However, unlike hospice patients, the prognosis for these patients is for a longer than 6 months; therefore, they may have very different additional needs.

Working definitions of "serious and complex illness" will require defining the thresholds of serious disability in an eventually fatal illness. Such a patient has a condition that causes suffering and/or disability every day and that will worsen over time and cause death. The Medicare criteria for home oxygen in chronic obstructive lung disease would seem to be a good threshold, for example. Having metastatic cancer or Class III heart failure despite medications could also be appropriate criteria. Dementia patients might qualify when they are mute, immobile, and incontinent. Persons with multiple illnesses will be common, and we will have to articulate rules that account for this complexity.

In addition, managed care organizations and regulators; the Veterans Healthcare System; and other population-based service providers could use patients with "serious and complex illness" to report symptom management, family support, and continuity. Certification or reporting standards could monitor how often these patients had the same provider team through to death, had symptoms controlled, had comprehensive plans for exacerbations, and had specific plans for the time of death. ${ }^{13}$ The measured rates could provide information for patient choice, as well as for quality improvement and for contracting standards.

\section{RELIABILITY AND CONTINUITY AS SYSTEM-WIDE GOALS}

Patients need to be able to rely upon their providers and the promises that they make regarding care. If a disruption must occur, the transition will require some 
time, and coerced transfer to a new provider will require reasonable allegiance by the new care team to decisions already made by the patient. For example, a person might have slowly worsening amyotrophic lateral sclerosis. The patient may be relying upon a physician who is willing to come to the home and who promises to come quickly if ever the patient feels seriously short of breath. That patient should not suddenly be required to use a physician who only sees patients in the office and is unfamiliar with any treatment for this condition except ventilator support.

The usual American coming to the end of life has every reason to fear the care system, even if he or she is at peace with the fact of mortality. By middle age, most Americans have experienced a loved one living out the end of life with unrelieved pain, avoidable but terrifying emergencies, or crushing care burdens on family. Indeed, when a person lives well despite fatal illness and then dies peacefully, family will say, "We were lucky." No one feels that good care is routine and reliable.

\section{CONTEMPORARY STRUCTURES AND FINANCING AS IMPEDIMENTS TO QUALITY CARE}

Many of the current dysfunction in the care of very sick and slowly dying people originate in or are perpetuated by the way that care is organized and financed. ${ }^{1,14}$ Providers who run profitable businesses in current financing and practice patterns are comfortable with and generally benefit from the fragmentation and specialization of the care system. Nevertheless, these structures and incentives act against the interests of people with multiple progressive problems who need continuity across a variety of services in various settings. In addition, current financing often does not encourage symptom relief, family support, and counseling.

The foci of reform in the organization and financing of care for serious and complex illnesses vary somewhat by the dominant course of illness in the last phase of life. Cancer care is heavily "medical" and covered by Medicare, including hospice at the end. Organ system failures, such as heart failure, cirrhosis, and obstructive lung disease, are also heavily treated in "medical" systems and the costs are borne largely by Medicare. However, organ system failure patients ordinarily cannot use hospice ${ }^{6}$ or any other service customized to provide good home support at the end of life. For those afflicted with strokes or dementia, the bulk of the care needs fall outside of a "medical" reimbursement model and these individuals are forced to rely much more upon personal assets, family, and Medicaid. Those afflicted with the multifactorial frailty of advanced old age have been unapparent in the "design" of the care system. They are most often served by a mix of care systems aimed at other populations and with financing from a variety of sources (usually a combination of Medicare, Medicaid, and personal wealth). The differences among these sorts of populations and the effects of organization and financing shape the possibilities for reform.
About three quarters of us die in care financed by Medicare. ${ }^{1}$ Another sizable group relies upon Medicaid or the VA health care system. Effectively, how most Americans live while facing fatal illness is already strongly determined by federal policies and financing. Yet, federal agencies, including Medicare, have no policy or monitors, no quality indicators, and no clear mission in this arena. Medicare's structure ends up being inimical to the interests of persons with long-term progressive disabilities and diseases that will end in death. Fee-for-service reimbursements pay better for discontinuity and for performing medical procedures, even though serious chronic illness calls for continuity, dependability, counseling, symptom management, and family support. Capitated payment systems do not yet adjust much for the increased costs of care for seriously ill persons, thus making it hazardous for any managed care provider to gain a reputation for excellence in this area. ${ }^{15}$

Costs for serious and complex illness at the end of life are quite substantial. Lubitz et al. ${ }^{16}$ have shown that $\$ 1$ of every $\$ 8$ spent by Medicare pays for care delivered in the last month of life, and $\$ 1$ of every $\$ 4$ is spent in the last year of life. Since most eventually fatal conditions are seriously disabling for more than the last year, Medicare probably spends more than a quarter of its funds for the treatment of serious, complex, and eventually fatal conditions. Of course, the rate might be right, but these substantial expenditures are not buying what people need and want.

\section{RECENT ADVANCES AND OPPORTUNITIES FOR REAL IMPROVEMENT}

Some recent innovations illuminate the opportunities for living well despite serious illness at the end of life. Hospice is an obvious example, providing care that ensures that most of their patients who are very near to death can live comfortably and meaningfully. ${ }^{17}$ The Program for AllInclusive Care of the Elderly has shown that programs for extensive community support and coordination for frail or demented elderly can be extremely valuable and successful. ${ }^{18}$ In congestive heart failure, a recent review of fairly rigorous trials of comprehensive and coordinated care (including self-care education, medications, exercise, and early intervention) showed that most have reduced hospitalizations by at least half, a result which not only indicates reduced utilization but also reflects suffering that was avoided. ${ }^{9}$ These gains are well documented, but most dying people will never receive this kind of care. To make quality care reliably available at the end of life for all of us, we need fundamental system-wide reform. ${ }^{19}$

Such reform has started, albeit slowly. Opinion leaders and ordinary Americans have only recently begun to recognize that the shortcomings of care at the end of life are a predictable result of how the care system is structured. Our problems at the end of life are not just the result of uninformed physicians or of patients in denial, 
though those undoubtedly contribute. Instead, while attending to other matters, we have put the care delivery system together in ways that ensure discontinuity, undertreat pain and other symptoms, discourage planning ahead or acknowledging the death that is in store, and pay so much less for reliable care that it is almost never a sustainable business strategy for providers. ${ }^{1}$

Some major gains have arisen in recent years, including the surge of attention given to end-of-life care. Many federal agencies, Congressional representatives, and leadership organizations in health care have voiced urgency in improving care for serious illness at the end of life. During the most recent Congress, 3 major bills were under consideration that stood to directly affect end-of-life care in this country. The National Institutes of Health has initiated a special request for proposals in end-of-life care. $^{20}$ The Department of Veterans Affairs has been especially diligent and effective in investing in change to improve care for serious chronic disease. They have instituted advance planning as a quality measure, started requiring pain to be measured as a fifth vital sign, developed a Faculty Scholars program in end-of-life care, and otherwise encouraged innovation and improvement. ${ }^{21}$

Additionally, not only have there been 2 chapters in the last 2 annual reports from the Medicare Payment Advisory Commission $^{3,22}$ and a good overview from a Committee of the Institute of Medicine, ${ }^{1}$ but an increasing array of researchers and innovators are engaged in these issues. The Robert Wood Johnson Foundation has funded 2 major sets of grants for improving end-of-life care which encompass research, innovation, state-based coordinating groups, and professional and public education. ${ }^{23}$ The Project on Death in America of the Open Society Institute has sponsored 54 full-time Faculty Scholars in academic medical centers, as well as multiple special and general grants programs. ${ }^{24}$ The American Medical Association has initiated a program to teach most physicians about end-oflife care Education of Physicians about End-of-Life Care. ${ }^{25}$ The American College of Physicians-American Society of Internal Medicine has convened a panel that is articulating best practices and educating membership about how to implement them. ${ }^{26}$ The Institute for Healthcare Improvement and others have sponsored 2 national Breakthrough Series Collaboratives to Improve Care at the End of Life. ${ }^{21,27}$

\section{CONCLUSION}

In light of the rapid aging of our population, serious and complex illness will affect many of us for at least a few years as we come to the ends of our lives. But until now, our measures, and even our conceptualizations, of good care simply did not reflect what might be best for the care for these persons with worsening illness who are not hospiceeligible. It is time for some additional measures, additional conceptualizations, and an additional categorization.

This is important because the categories that we take to be relevant shape the possibilities for improvement. Until recently, our society envisioned only "terminally ill" as the category of concern for public policy, quality measurement, and quality improvement. The terminology we use implies that those patients are discernibly different from all others and that they are appropriate only for "palliative care." Only those patients can have hospice care, and some feel that only these persons can also avail themselves of physician assistance in suicide. ${ }^{28}$ Yet, some of those who are "sick enough to die," and who do in fact die of their illnesses, never have a period that can be labeled as "terminal."

"Serious and complex illness" could be the broader category that would prove useful as public policy efforts move forward. Many of us die after months or years of living with serious chronic illness and an uncertain prognosis and the priority on rescue and the tolerance of episodic care that mark the usual care system are sadly mismatched to the preferences and possibilities for a person who has a serious, progressive, irreversible, and eventually fatal illness. Perhaps working with this population would teach us how to provide services that are more appropriate and how to finance care for this population more reasonably. Recognizing this category would trigger special priorities for symptom management, family support, continuity, planning, and related care needs. The time has come to reprioritize and repackage the health care services provided to those with "serious and complex illness" and thereby allow patient care to suit patient needs.

\section{REFERENCES}

1. Institute of Medicine. Field, MJ \& Cassel, CK, eds. Approaching Death: Improving Care at the End of Life. Washington, DC: National Academy Press; 1997.

2. Patient's Bill of Rights Act of 1998: A Health Insurance Bill of Rights (S.2529).

3. Presidential Memorandum Regarding Federal Agency Compliance with the Patient's Bill of Rights. February 20, 1998.

4. Chrvala CA, Sharfstein S, eds. Definition of Serious and Complex Medical Conditions. Washington, DC: National Academy Press; 1999.

5. Lynn J. Potentially ineffective care in intensive care [letter]. JAMA. 1998;279:652.

6. Fox E, Landrum-McNiff K, Zhong Z, Dawson NV, Wu AW, Lynn J. Evaluation of prognostic criteria for determining hospice eligibility in patients with advanced lung, heart or liver disease. SUPPORT Investigators Study to Understand Prognosis and Preferences for Outcomes and Risks of Treatment. JAMA. 1999;282: 1638-45.

7. Hammes BJ, Rooney BL. Death and end-of-life planning in one Midwestern community. Arch Intern Med. 1998;158:383-90.

8. Lynn J, Harrell F, Cohn F, Wagner D, Connors AF Jr. Prognoses of seriously ill hospitalized patients on the days before death: implications for patient care and public policy. New Horiz. 1997;5:56-61.

9. Rich MW. Heart failure disease management: a critical review. J Cardiac Fail. 1999;5:64-75.

10. Lynn J, Teno JM, Harrell FE. Accurate prognostications of death. Opportunities and challenges for clinicians. West J Med. 1995; 63:250-7.

11. Memorandum to National Hospice Organization State and Provider Organizations by then-President Jay Mahoney. OIG Final Report: Hospice Patients in Nursing Homes. September 25, 1997. 
12. Lynn J. Measuring quality of care at the end-of-life: a statement of principles. J Am Geriatr Soc. 1997;45:526-7.

13. Foundation for Accountability (FACCT). A Consumer Voice on Health Care Quality. Portland, Or: FACCT; 1996.

14. Medicare Payment Advisory Commission. Report to the Congress: Selected Medicare Issues. Washington, DC; MedPAC: 1999.

15. Iezzoni LI, Ayanian JZ, Bates DW, Burstin HR. Sounding Board: Paying more fairly for Medicare capitated care. N Engl $\mathrm{J}$ Med. 1998;339;1933-8.

16. Lubitz JD, Riley GF. Trends in Medicare payments in the last year of life. N Engl J Med. 1993;328:1092-6.

17. Lamers WM. Hospice: enhancing the quality of life. Oncology. 1990;4:121-6.

18. Kane RL. PACE: a model of integrated acute and long-term care. Hosp Pract (Off Ed). 1997;32:23-4, 27, 30.

19. Berwick D. Quality comes home. Ann Intern Med. 1996;125: 839-43.

20. Available at The National Institutes of Health Office of Extramural Research home page at: http://www.nih.gov/grants/guide/ rfa-files/RFA-NR-99-004.html.
21. Lynn J, Schuster JL. Improving Care for the End-of-Life: A Sourcebook for Health Care Managers and Clinicians. New York, NY; Oxford University Press; 2000.

22. Medicare Payment Advisory Commission. Report to the Congress: Context for a Changing Medicare Program. Washington, DC; MedPAC: 1998.

23. Available at The Robert Wood Johnson Foundation home page at: http://rwjf.org/main.html.

24. Available at the Project on Death in America home page at: http:// www.soros.org/death/@pdia.htm.

25. Available at the home page for the American Medical Association Education for Physicians about End-of-Life Care (EPEC) Project at: http://www.ama-assn.org/ethic/epec/index.htm.

26. Lo B, Snyder L, Sox HC. Care at the End of Life: guiding practice where there are no easy answers. Ann Intern Med. 1999;130:772-3.

27. Lynn J, Schall MW, Milne C, Nolan KM, Kabcenell A. Quality improvements in end-of-life care: insights from two collaboratives. Joint Comm J Qual Improv. 2000;26:254-67.

28. Battin MP. Euthanasia: the way we do it, the way they do it. J Pain Symptom Manage. 1991;6:298-305.

YOU'RE INVITED TO VISIT

The SGIM Website

Portal \& Pathway

to Professional Effectiveness \& Satisfaction offering

Knowledge - Networking - Career Development

Featuring links to resources \& tools

including meetings, publications, job listings, funding

sources, Residency \& Fellowship directories, government

agencies,

$\&$ search engines

Located at http://www.sgim.org 